\title{
Intelligent Monitoring, Stability Evaluation, and Landslide Treatment of a Carbonaceous Mudstone and Shale Slope in Guangxi, China
}

\author{
Junhui Luo ${ }^{1,2 *}$, Decai Mi ${ }^{3}$, Haifeng Huang ${ }^{2}$, Tao Zhang ${ }^{4}$, Guanhua Sun ${ }^{5}$, Deqiang Chen ${ }^{6}$ \\ ${ }^{1}$ Guangxi Xinfazhan Communications Group Co., LTD, Nanning 530029, China \\ ${ }^{2}$ Guangxi Beitou Transportation Maintenance Technology Group Co., LTD, Nanning 530029, China \\ ${ }^{3}$ Guangxi Communication Design Group Co., LTD, Nanning 530029, China \\ ${ }^{4}$ Faculty of Engineering, China University of Geosciences, Wuhan 430074, China \\ ${ }^{5}$ State Key Laboratory of Geomechanics and Geotechnical Engineering, Institute of Rock and Soil Mechanics, Chinese \\ Academy of Sciences, Wuhan 430071, China \\ ${ }^{6}$ College of Civil Engineering and Architecture, Guangxi University, Nanning 530004, China
}

Corresponding Author Email: 230129405@seu.edu.cn

https://doi.org/10.18280/ijsse.100309

Received: 5 November 2019

Accepted: 20 April 2020

\section{Keywords:}

carbonaceous mudstone and shale (CMS), stability evaluation, intelligent monitoring, landslide treatment

\begin{abstract}
Carbonaceous mudstone and shale (CMS) slopes are prone to disintegration, instability, and other engineering diseases. This calls for a suitable method to evaluate the slope stability and eliminate the hazards. However, the traditional slope monitoring system is slow in alarm and response, and inaccurate in stability analysis. Based on the BeiDou Navigation Satellite System (BDS), this paper designs a novel automatic monitoring and early warning system. In the system, the limit equilibrium method was combined with the Slope ${ }^{\mathrm{SR}}$ finite-element method that satisfies the inequality relationship to evaluate the slope stability. The reliability of the proposed system was verified through an example analysis on a CMS landslide slope in Guangxi, China. Through field survey on the slope, the geological conditions of the slope were identified, so were the features of slip mass, slip band, and slip bed. Finally, the comprehensive treatment plan was designed for the slope. The results show that: (1) Under natural condition, the slope is temporarily stable. If heavy rainfall occurs in the study area, the slope is very likely to slide on a large scale. (2) The maximum residual sliding force of A main-A main' section was $54.861 \mathrm{kN} / \mathrm{m}$. The calculated displacement meets the development trend of the landslide slope, as evidenced by the results of Slope ${ }^{\mathrm{SR}}$ finite-element simulation. (3) The CMS slope became safe and stable after being fortified with anchor-cable lattice beam + anti-slide pile + gravity concrete retaining wall + drainage measures + monitoring measures.
\end{abstract}

\section{INTRODUCTION}

The highway mileage in China is growing year by year. In the meantime, more and more highway slopes face the risk of instability, which brings serious problems like the loss of life and property. The slope monitoring system can issue an alarm in advance to prevent slope stability accidents. Slope safety is traditionally monitored by point stability analysis. However, this traditional technique has many defects, namely, low automation, slow reporting, long response time, and incomplete functions. The high false alarm rate of the technique makes it difficult to prevent and treat safety accident in an effective and timely manner. Therefore, many scholars have strived to design a better slope monitoring system [1].

For instance, Feng et al. [2] analyzed the deformation trend and stability of a high cut slope by multi-angle monitoring, and timely forecasted and warned the occurrence of geological disasters on the slope. Based on the BeiDou Navigation Satellite System (BDS), Singhal et al. proposed an intelligent slope monitoring and early warning system, which effectively reduces the workload of slope management personnel [3]. Considering the distribution of water content in wetting layer and the seepage effect in saturated layer, Su et al. [4] extended
Green-Ampt (GA) model into the LSGA model of rainwater infiltration, and established the expression of slope stability coefficient.

In addition, Lin et al. [5] combined strength reduction method and $\varphi-v$ inequality with the incremental method of elastoplastic mechanics and bilinear projection operator, creating a virtual element strength reduction technique for slope stability analysis. Li et al. surveyed the occurrence of slopes and dominant structural planes in a mining area, and integrated flat projection, limit equilibrium method with numerical analysis to improve the reliability of slope stability analysis. Luo et al. derived the expression of the slope safety factor for the double reduction method, and designed two judgement criteria for precision and strength weakening, respectively [6, 7]. Using the improved formula of Morgenstern-Price method, Lei et al. [8] calculated the stability of anchored slopes, and outputted similar results as the simulation data.

So far, extensive studies have been done on slope monitoring [9-11] and slope stability analysis [12-14]. But there is little report on the intelligent monitoring and stability analysis for carbonaceous mudstone and shale (CMS) slopes. Based on the BDS, this paper develops a novel automatic 
monitoring and early warning system for the stability of CMS slopes. The system couples the limit equilibrium method and the Slope ${ }^{\mathrm{SR}}$ finite-element method. Then, the proposed system was applied to evaluate the stability of a CMS landslide slope in Guagnxi, China. Finally, a reasonable treatment plan was prepared based on the evaluation results and site survey report [15-20].

\section{ENGINEERING DISEASE ANALYSIS}

The CMS is prone to disintegration and softening. As a result, CMS slopes are susceptible to instability, calling for special research into slope stability.

\subsection{Study area}

The slope is located at the junction of Nanxin East Road and Xinhua Road, Jinchengjiang District, Hechi City, southwestern China's Guangxi Zhuang Autonomous Region. The location belongs to Third Junior High School of Jinchengjiang District, a key secondary school in that city. Since 2016, cracks appeared in the ground and walls in the school, posing a serious threat to personnel safety.

(1) Meteorology and hydrology.Rainfall is the main form of atmospheric precipitation in the study area. The rainwater infiltrates the landslide slope, which increases the weight of the soil, and weakens the mechanical strength of the slip mass. The infiltration also creates an underflow beneath the slip surface, undermining the mechanical balance of the slope.

(2) Landform.The CMS landslide slope is on the south of the Jiulong Mountain (peak elevation: $251.3 \mathrm{~m}$ ). The study area has a hilly landform. The hidden hazard of landslide falls on the southern slope.

\subsection{Stratigraphic lithology}

According to regional geological data, surface geological survey, drilling, and trenching, the overburden of the study area is Quaternary fill $\left(\mathrm{Q}^{\mathrm{ml}}\right)$, and Quaternary clay $\left(\mathrm{Q}^{\mathrm{dl}+\mathrm{el}}\right)$ of residual slopes; the underlying bedrock is the CMS of Lower Carboniferous Datang Stage $\left(\mathrm{C}_{1} \mathrm{~d}\right)$.

The completely to strongly weathered CMS are grayish black or reddish brown. Most of them are completely weathered, with a thin layer $(0.3-0.8 \mathrm{~m})$ of strongly weathered CMS in local places. The distribution of the CMS is very uneven.

The slope is a dip slope with the rock formation oriented at $160^{\circ} \angle 18^{\circ}$. The rock structure has basically been destroyed. The soil-like core can be crushed by hand, featuring developed joints and fissures.

The CMS belong to a stable underlying rock and soil layer in the slope. This layer is thick in some places. Trenching shows that the thickness of the layer is between 1.4 and $23.5 \mathrm{~m}$.

Through the above analysis, the completely to strongly weathered CMS are easy to disintegrate. This is the major cause of slope instability.

\subsection{Geological structure}

Over the long geosocial history, the study area was subjected to multiple tectonic movements. The folds and faults are highly developed, leading to a complex geological structure. The hidden hazard of landslide lies at $0.8 \mathrm{~km}$ south of the Hechi compressive fault. There is no fault that passes through the study area.

With a clay overburden, the soil in the study area is of medium softness. Thus, the study area is a Class II site. The local area of the slope has good stability, and favorable geological structure. In terms of seismic intensity, the study area belongs to Level VI, where peak acceleration of ground motion is $0.05 \mathrm{~g}$. The design earthquake group, the characteristic period of the seismic response spectrum, and the seismic fortification of the study area are Group I, 0.35s, and Level VII, respectively.

\subsection{Boundaries, scale and morphology}

The field survey shows that the strong deformation area cracked after 2016. Two semi-arc tensile cracks appeared before the teaching building and behind the comprehensive teaching building, respectively. These cracks constitute the rear edge of the landslide slope. The western edge of the slope is marked by the shear crack on the stairs to the west of the slip mass.

In plane view, the landslide slope is shaped like a semicircle (Figure 1). The rear and front edges of the slip mass are $221.5 \mathrm{~m}$ and $194.9 \mathrm{~m}$ in elevation, respectively, i.e. the relative height difference is $17.6 \mathrm{~m}$.

The slope is $85 \mathrm{~m}$ in length and $84 \mathrm{~m}$ in average width. With an average thickness of $8 \mathrm{~m}$, the slip mass mainly slides in the direction of $193^{\circ}$. The estimated volume of the slip mass is small $\left(5.7 \times 104 \mathrm{~m}^{3}\right)$.

The cracks on the rear edge are not obvious. There are 5 cracks in the middle of the slip mass. Among them, the tensile cracks are $0.6-1.2 \mathrm{~cm}$ in width, $2.1-39 \mathrm{~m}$ in length, and $1.0 \mathrm{~m}$ in visible depth.

The landslide is mainly formed due to the nature of the rock and soil mass and the effect of heavy rainfall. Artificial cuts are present at the foot and on the surface of the slope. The terrain is undulating on the slope.

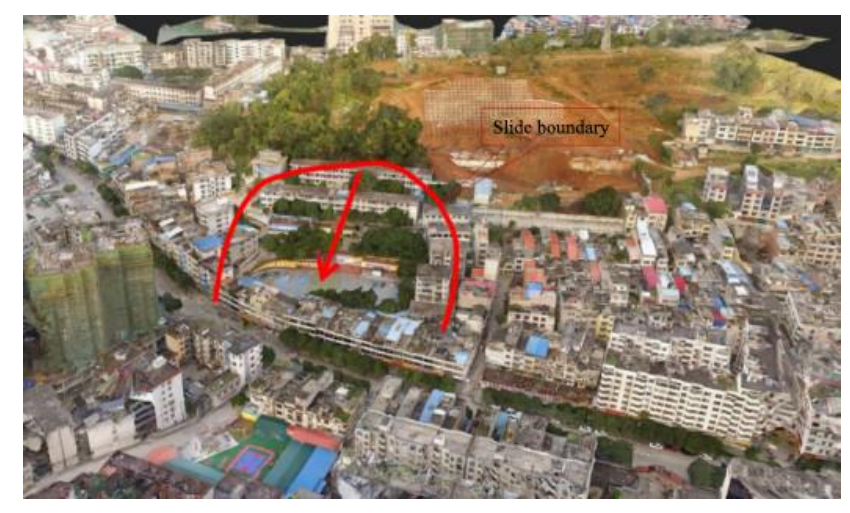

Figure 1. Full view of CMS landslide slope (shooting angle: $180^{\circ}$ )

\subsection{Features of slip mass}

Based on geological survey, trenching and drilling, the slip mass is miscellaneous fill and Quaternary clay of residual slopes. Observed in every borehole, the clay was found to have a hard plastic from, no shaking response, medium dry strength, medium toughness, and slight smoothness.

According to the tests on composition, soil and physicalmechanical properties, the soil in the landslide slope have low mechanical strength and poor erosion resistance. 


\subsection{Features of slip band and slip bed}

\subsubsection{Features of slip band}

During geological survey and trenching, the soil mass became much softer at the interface between clay and CMS. There is a $0.2-0.4 \mathrm{~m}$-thick layer of delicate soft soil, which can be determined as the slip band. During drilling, the drill bit moved faster upon reaching this layer.

The soft soil layer could be attributed to the rising groundwater after rainfall. Due to the poor permeability of the underlying CMS, the soil directly above the CMS is saturated and softened (Figure 2).

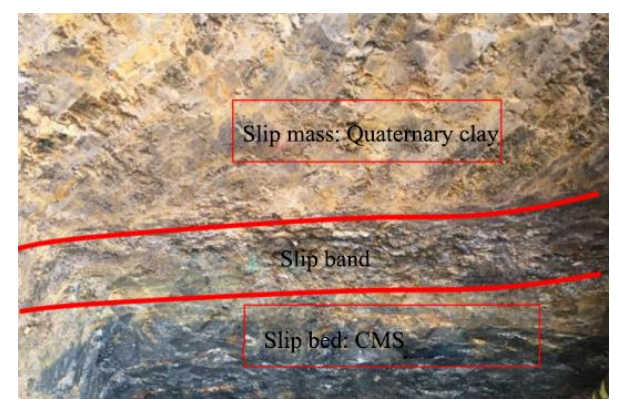

Figure 2. Slip mass, slip soil and slip bed

\subsubsection{Features of slip bed}

The slip bed of the landslide slope is completely to strongly weathered CMS. Through drilling, the slip bed was observed as a 5.0m-thick grayish black layer, in which most rock structure is destroyed and the mineral composition has changed. Besides, weathered fissures are developed, while rock masses are broken and weathered into clay. Drilling data show that the CMS contain lots of water and exist in hard plastic to plastic form.

\section{STABILITY ANALYSIS}

\subsection{Field monitoring and treatment analysis}

The project team conducted rainfall monitoring and displacement monitoring. The displacements on and within the slope were monitored by the BDS and cable-type displacement gauge.

\subsubsection{Trend of landslide development}

At present, the landslide slope has not slid as a whole. Recently, tension formed in the upper part at the front and middle of the slip mass, resulting in a clear growth in shear cracks. The slope is in the creep deformation stage. Under heavy rain, the main body of the slope is unstable. The landslide hazard belongs to Class I.

\subsubsection{Sensitivity analysis of influencing factors}

The landslide is mainly affected by the strength parameters of the slip band, namely, cohesion $\mathrm{C}$ and internal friction angle $\varphi$. Despite the rise and fall of groundwater level, cohesion only changes slightly in the skeleton, exerting a limited impact to slope stability. Meanwhile, the internal friction angle changed greatly, which greatly affects the slope stability.

\subsubsection{Recommended values of geotechnical parameters}

The physical and mechanical parameters of the rock and soil layers in the slope were recommended (Table 1), according to the engineering geological features of rock and soil mass revealed by drilling, the results of geotechnical tests, as well as work experience.

Table 1. Recommended values of geotechnical parameters

\begin{tabular}{|c|c|c|c|}
\hline $\begin{array}{c}\begin{array}{c}\text { Name of } \\
\text { layer }\end{array} \\
\end{array}$ & $\begin{array}{c}\text { Bulk density } \\
\left(\mathrm{kN} / \mathrm{m}^{3}\right)\end{array}$ & $\begin{array}{c}\text { Cohesion } \\
(\mathbf{k P a})\end{array}$ & $\begin{array}{c}\text { Internal friction } \\
\text { angle } \varphi\left({ }^{\circ}\right) \\
\end{array}$ \\
\hline Clay (slip soil) 1 & 18.18 & 19.22 & 13.9 \\
\hline Clay (slip soil) 2 & 19.20 & 15.221 & 10.55 \\
\hline CMS 1 & 18.00 & 50.0 & 20 \\
\hline CMS 2 & 18.60 & 46 & 18 \\
\hline
\end{tabular}

\subsection{Slope stability analysis}

\subsubsection{Analysis based on limit equilibrium method}

(1) Calculation model and working conditions

1) Calculation model. The landslide hazard in the slope was classified to Level I. The slip surface, located on the contact between the overburden and the CMS, can be approximated as a polyline. By the limit equilibrium method, the main longitudinal section of the landslide slope, i.e. A main-A main' section, was selected for stability calculation.

2) Working conditions. Sustained heavy rainfall is the leading cause of slope deformation and failure, and the major influencing factor of slope stability. Hence, three working conditions were designed to compute the stability and thrust of A main-A main' section:

Working condition I: Natural condition, only considering the weight of the slip mass.

Working condition II: Weight + rainstorm + groundwater; the slip mass is saturated; the slip surface has groundwater.

Working condition III: Weight + earthquake + groundwater; the slip mass is hit by a magnitude 7 earthquake, and saturated; the slip surface has groundwater.

(2) Calculation method and parameter selection

1) Calculation method

The polyline stability coefficient k can be calculated by:

$$
F_{S}=\frac{\sum_{i=1}^{n-1}\left(R_{i} \prod_{j=i}^{n-1} \phi_{j}\right)+R_{n}}{\sum_{i=1}^{n-1}\left(T_{i} \prod_{j=i}^{n-1} \phi_{j}\right)+T_{n}}
$$

where, $F_{S}$ is the landslide stability coefficient; $\varphi_{i}$ is the transfer coefficient of slip surface $i(j=1) ; R_{i}$ is the anti-slip force on slip surface $i(\mathrm{kN} / \mathrm{m}) ; W_{i}$ is the weight of slip surface $\mathrm{i}(\mathrm{kN}) ; L_{i}$ is the length of slip surface $i(\mathrm{~m}) ; a_{i}$ is the dip angle of slip surface $i\left(^{\circ}\right) ; \varphi_{i}$ is the internal friction angle of slip surface $i\left(^{\circ}\right)$; $R_{n}$ is the anti-slip force on slip surface $n(\mathrm{kN}) ; T_{i}$ is the sliding force on slip surface $i(\mathrm{kN})$, which is negative if the force is along the sliding direction; $T_{n}$ is the residual sliding force on slip surface $n(\mathrm{kN})$.

\section{2) Parameter selection}

Based on geotechnical test, field high shear test, field high bulk density test, and regional experience, the saturation bulk densities of clay and the CMS were determined as $19.20 \mathrm{kN} / \mathrm{m}^{3}$, and $18.60 \mathrm{kN} / \mathrm{m}^{3}$, respectively.

For accurate evaluation of slope stability, the shear strength parameters of the soil masses must be selected reasonably. Here, $\mathrm{C}$ and $\varphi$ values are determined as $19.22 \mathrm{kPa}$ and $13.9^{\circ}$ under natural condition, and $15.22 \mathrm{kPa}$ and $10.55^{\circ}$ under saturated condition, according to indoor test, field large shear test, inversion, and regional experience. 
The buildings of the school were built many years ago with heavy building materials. Hence, the additional load was set to $21 \mathrm{kN} / \mathrm{m}^{2}$.

Based on the above parameter settings, the stability coefficients of the A main-A main' section under the three working conditions were calculated by limit equilibrium method. The calculated results are listed in Table 4.

The slope stability was graded by the following criteria: If $F_{S} \geq 1.15$, the slope is stable; if $F_{S}=1.15-1.05$, the slope is basically stable; if $F_{S}=1.00-1.05$, the slope is under-stable; if $F_{S}<1.00$, the slope is instable. The following conclusions were drawn from these criteria:

Under working condition I (weight): the stability coefficient of A main-A main' section $F_{S}=1.260$, indicating that the slope is stable.

Under working condition II (weight + rainstorm + groundwater): the stability coefficient of A main-A main' section $F_{S}=0.963$, indicating that the slope is instable.

Under working condition III (weight + earthquake + groundwater): the stability coefficient of A main-A main' section $F_{S}=1.210$, indicating that the slope is stable.

The calculated results agree with the field survey: In June
2017 , the study area was hit by sustained heavy rainfall. The shear cracks widened in the middle and lower parts of the slope, and tensile cracks appeared on the surface of the slip mass. Water seeped from the shear outlet on the front edge. The entire slip mass underwent creep deformation, falling in the overall deformation-sliding state.

As the working condition worsened, the slope stability state changed from basically stable to instable, resulting in the overall sliding of the slope.

(3) Thrust calculation and evaluation

The thrust of the slope was measured by the residual sliding forces of different slip surfaces under the three working conditions. The landslide prevention of the slope was classified as Level I, according to the affected objects, degree of disaster, construction difficulty and project investment. On this basis, the residual sliding forces and safety coefficients of the slope were calculated. The calculated results are listed in Table 2 below.

The maximum residual sliding force was taken as the final sliding force of A main-A main' section, that is, $54.861 \mathrm{kN}$ under working condition III.

Table 2. The calculated values of residual sliding force

\begin{tabular}{ccccccc}
\hline Section & $\begin{array}{c}\text { Working } \\
\text { condition }\end{array}$ & Load (s) & $\begin{array}{c}\text { Calculated } \\
\text { value of } \boldsymbol{F} \boldsymbol{S}\end{array}$ & Stability & $\begin{array}{c}\text { Safety } \\
\text { coefficient }\end{array}$ & $\begin{array}{c}\text { Residual sliding } \\
\text { force (kN) }\end{array}$ \\
\hline A main-A & I & Weight & 1.260 & Stable & 1.40 & 12.030 \\
main' & II & Weight + rainstorm + groundwater & 0.963 & Instable & 1.15 & 54.861 \\
section & III & Weight + earthquake + groundwater & 1.210 & Stable & 1.15 & 0 \\
\hline
\end{tabular}

\subsubsection{Slope SR $^{\mathrm{SR}}$-based calculation of slope stability}

(1) Slope ${ }^{\mathrm{SR}}$ method that satisfies the inequality relationship

The finite-element strength reduction method was proposed by Zienkiewicz et al. [21]. In 1975, Zienkiewicz et al. invented the concept of shear strength reduction coefficient in the finiteelement simulation of elastoplastic geomaterials. The coefficient is defined as the ratio of the maximum shear strength of the rock and soil mass in the slope to the actual shear stress in the slope produced by a constant external load.

Under the Mohr-Coulomb criterion, the shear strength can be reduced iteratively by:

$$
\begin{gathered}
c_{i}=\frac{c}{F_{S}} \\
\tan \varphi_{i}=\frac{\tan \varphi}{F_{S}}
\end{gathered}
$$

$$
\begin{aligned}
& \text { s.t. } \\
& \sin \psi>1-2 v
\end{aligned}
$$

where, $c_{i}$ and $\tan \varphi_{i}$ are the strength parameters of the material used in the $i$-th finite element calculation. The calculation proceeds iteratively until the slope fails. The iterative calculation is implemented in the procedure of Figure 3.

The calculation interface of Slope ${ }^{\mathrm{SR}}$ (Figure 4) integrates the Zienkiewicz's strength reduction method and the finiteelement calculation of elastoplastic geomaterials. These two methods have been repeatedly integrated and applied to evaluate slope stability. The core of the integrated approach is the finite-element calculation.

By the integrated approach, the slope strength is firstly reduced, followed by nonlinear finite-element analysis on slope stability. After the strength reduction, a plastic zone will appear in the slope. When the slope slips, the plastic strain near the shear plane is much larger than that on the two sides. Thus, the slip surface must pass the point of peak plastic strain. Then, the connecting line passing through the ridge of the contour line can be regarded as the most dangerous slip surface. This phenomenon has been confirmed by many indoor experiments.

Compared with the classic method of slices, the hybrid approach has various advantages: it satisfies all kinds of equilibrium conditions; it applies to slopes with complex terrains and geologies; it considers the nonlinear elastoplastic constitutive relationship of the material, and the effect of deformation on stress; it can simulate the instability process of the slope and the shape of the slip surface; it can simulate the interaction between slope and support and other more complicated coupling processes; it can solve the stability coefficient without slicing or knowing the shape of the slip surface.

Thanks to development of computer technology, especially nonlinear elastoplastic finite-element calculation for geomaterials, many largescale general-purpose finite-element software have emerged for geomaterials. Every software boasts powerful functions of preprocessing and postprocessing, creating a favorable condition for finite-element analysis of slope stability. The software development further amplifies the advantages of the hybrid approach. That is why the approach has been popular in engineering and widely embedded in well-known geotechnical analysis software. 


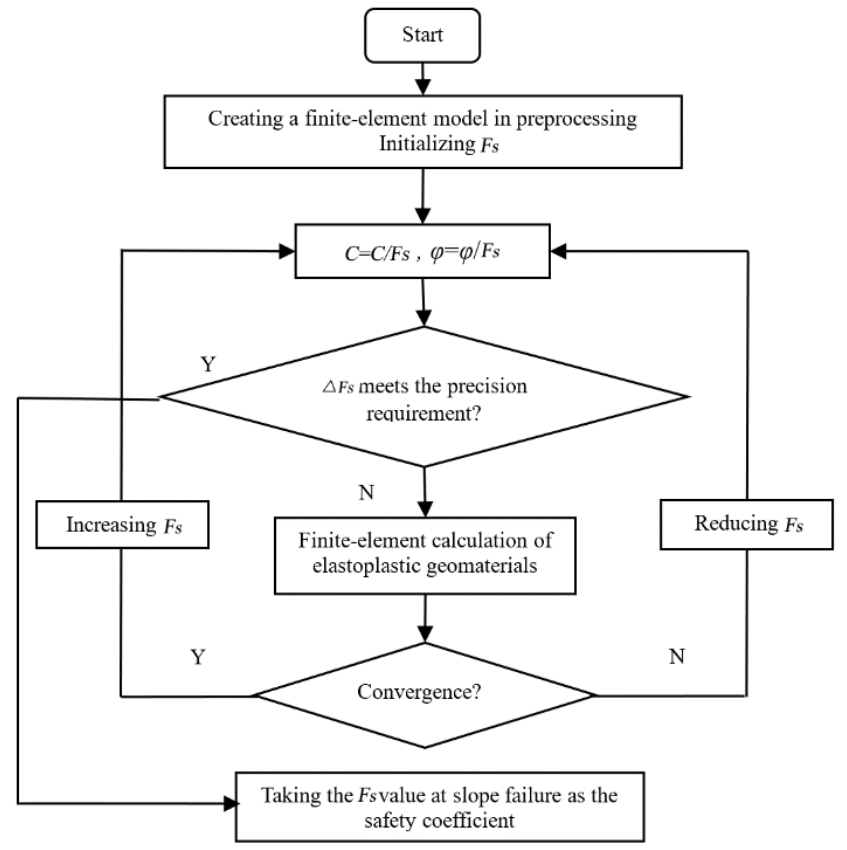

Figure 3. Workflow of strength reduction

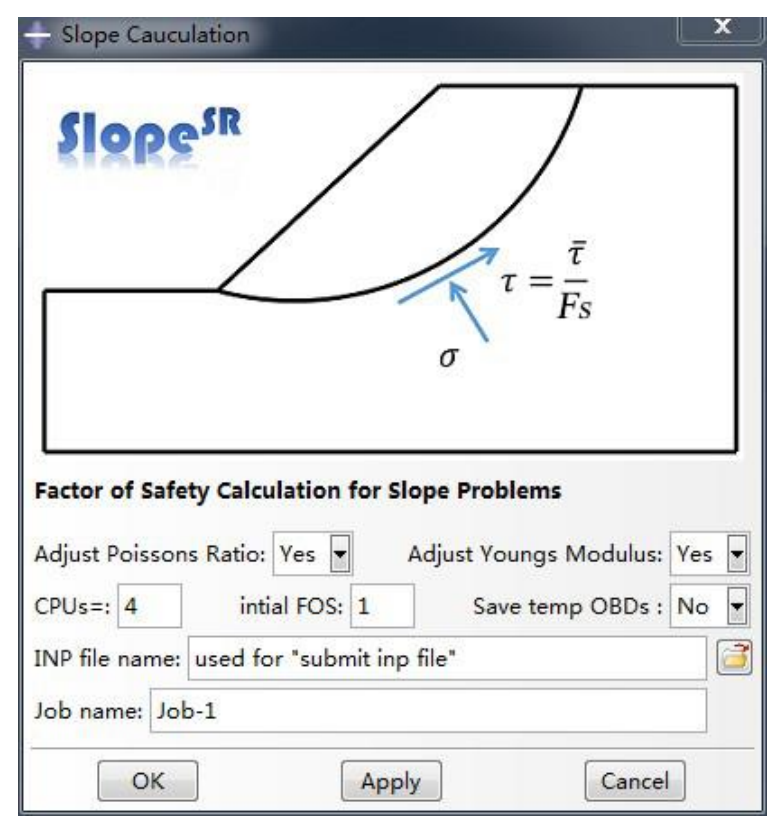

Figure 4. Calculation interface of Slope $\mathrm{SR}^{\mathrm{SR}}$

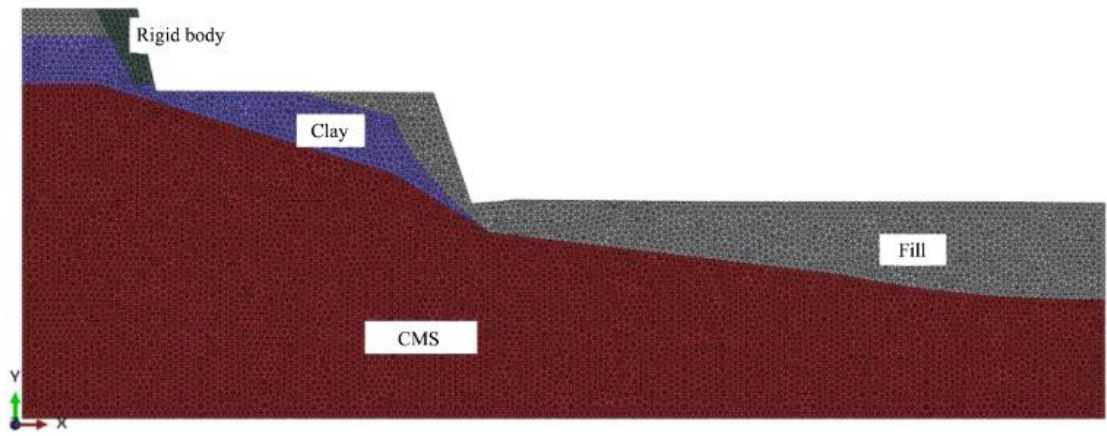

Figure 5. Finite-element model of CMS

Table 3. Basic physical-mechanical parameters of each layer

\begin{tabular}{cccccc}
\hline Layer name & Density & Young's modulus & Poisson's ratio & Internal friction angle & Cohesion \\
\hline Fill & 18.4 & 6,000 & 0.3 & 15 & 12 \\
Rigid mass & 100 & $1 \mathrm{e}+10$ & 0.3 & $/$ & $/$ \\
CMS & 22 & 6,000 & 0.3 & 11 & 15 \\
Clay & 18.4 & 6,000 & 0.3 & 15 & 22 \\
\hline
\end{tabular}

(2) Modelling and results analysis

The stability of the CMS slope was calculated by the Abaqus plug-in Slope ${ }^{\mathrm{SR}}$. The slope was imported to the plugin and meshed into grids (Figure 5). The parameters of the model are configured as Table 3 .

The boundry conditions of the model were set as follows: the left and right boundaries limit horizontal displacement, while the bottom boundary was fixed to limit vertical displacement. The building load was applied to the slope. Then, the soil gravity, load and time step were configured.

As shown in Figure 6, the dispalcement gradually decreased from the outside to the inside, showing an obvious slip trend. After the building load was applied, the peak displacement was observed at the soil mass beneath the building; the displacement gradually decreased from inside to outside, showing an obvious stratification. The displacement is inversely proportional to the soil depth. The deeper the soil layer, the smaller the effect of the load on the soil, and the smaller the displacement. The displacement contour was corrugated.

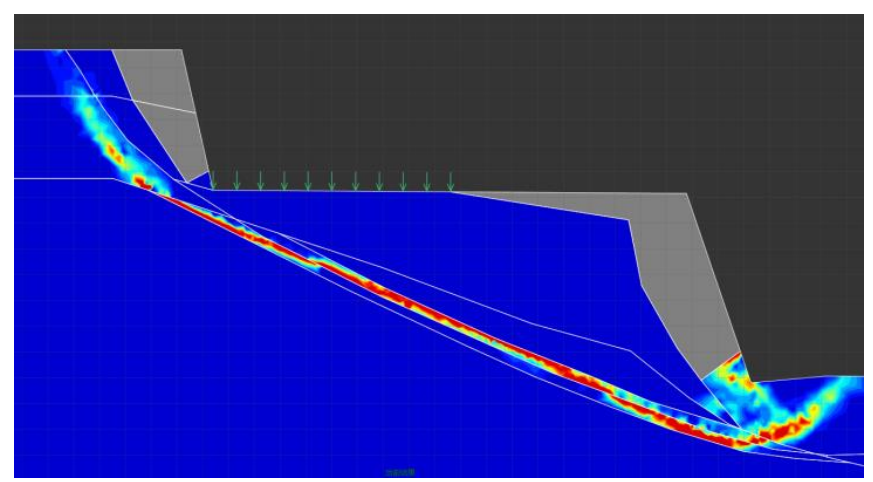

Figure 6. The contour map of total displacement at the end of iteration 


\subsection{Treatment measures}

(1) Plan 1: Anchor-cable lattice beam + anti-slide pile + gravity concrete retaining wall + drainage measures + monitoring measures.

On the upside, the teaching activities at the school could partially resume after the anti-slide pile + gravity concrete retaining wall are completed. The treatment requires a short cycle and a low cost. On the downside, the building foundations might be damaged in the construction process.

(2) Plan 2: Demolition of buildings above the slip mass + slope cutting and unloading + reinforcement with anchorcable lattice beam + drainage measures + monitoring measures.

On the upside, this plan can completely eliminate the hazard of landslide. On the downside, the treatment cycle is very long, and the cost cannot be accurately estimated, for the planning of future buildings is unknown. However, Plan 2 can be predicted to incur a much higher cost than Plan 1, and bring a high construction risk.

Overall, Plan 1 was selected to treat the CMS, and the construction process was strictly managed and controlled. In this way, the slope stability was effectively guaranteed.

\section{CONCLUSIONS}

This paper proposes a novel BDS-based automatic monitoring and early warning system for CMS slopes, which evaluates the slope stability with Slope ${ }^{\mathrm{SR}}$. The proposed system can efficiently predict the slope development, and issue alarms of landslide in time, thereby reducing the loss of life and property. The evaluation results were compared with field observation. The following conclusions were obtained:

Through geological survey, the distribution and parameters of the rock and soil mass in the slope were clarified, the cause and stability of the landslide slope were determined, and measures were designed to prevent the landslide, laying a solid basis for slope treatment in the study area.

In plane view, the slope is a small semi-circular thrust-type landslide slope. The slip mass mainly consists of miscellaneous fill and Quaternary clay of residual slopes. Under natural condition, the slope is temporarily stable. If heavy rainfall occurs in the study area, the slope is very likely to slide on a large scale.

The slope stability was qualified and quantified as follows:

(1) Under working condition I (weight): the stability coefficient of A main-A main' section $F_{S}=1.260$, indicating that the slope is stable.

(2) Under working condition II (weight + rainstorm + groundwater): the stability coefficient of A main-A main' section $F_{S}=0.963$, indicating that the slope is instable.

(3) Under working condition III (weight + earthquake + groundwater): the stability coefficient of A main-A main' section $\mathrm{K}=1.210$, indicating that the slope is stable.

Overall, the sections of the slope were stable under selfweight, basically stable or instable under weight + rainstorm + groundwater, and stable under weight + earthquake + groundwater.

The slope was divided into two parts for treatment. The maximum residual sliding force was taken as the final sliding force of A main-A main' section, that is, $54.861 \mathrm{kN}$ under working condition III.

\section{ACKNOWLEDGMENT}

The study was supported by the science and technology project of Guangxi "Research on the Key Technologies of highway construction in Guangxi carbonaceous rock area"(Grant No.: GuikeAC16380119) and "Research and Application of ecological slope protection technology in carbonaceous rock slope"(Grant No.: AD19110124).

\section{REFERENCES}

[1] Yu, Z., Li, B., Huang, C. (2018). Research on limit equilibrium method of three-dimensional slope stability. Archive of Applied Mechanics, 88(7): 1175-1186. https://doi.org/10.1007/s00419-018-1365-y

[2] Feng, X., Li, S., Yuan, C., Zeng, P., Sun, Y. (2018). Prediction of slope stability using naive Bayes classifier. KSCE Journal of Civil Engineering, 22(3): 941-950. https://doi.org/10.1007/s12205-018-1337-3

[3] Singhal, S., Mukherjee, P.K., Saini, N.K., Dutt, S., Kumar, R. (2019). Effect of carbon on major element analysis of carbonaceous silicate rocks by WD-XRF: An evaluation of error and its correction. Geochemistry: Exploration, Environment, Analysis, 19(1): 31-38. https://doi.org/10.1144/geochem2017-077

[4] Su, Y.H., Li, C.C. (2020). Stability analysis of slope based on Green-Ampt model under heavy rainfall. Rock and Soil Mechanics, 41(2): 389-398. https://doi.org/10.16285/j.rsm.2019.0001

[5] Lin, S., Guo, Y.K., Sun, G.H., Yang, Y.T., Zhang, G.H. (2019). Virtual element strength reduction method for slope stability analysis. Journal of Rock Mechanics and Engineering, 38(S2): 3429-3438

[6] Luo, J.H., Mi, D.C., Ye, Q.Y., Sun, G.H., Chen, D.Q. (2020). Study on microscopic characteristics and physical and mechanical parameters of carbonaceous rocks. In Materials Science Forum, Trans Tech Publications $\quad$ Ltd., 980: 368-376. https://doi.org/10.4028/www.scientific.net/MSF.980.36 8

[7] Zhang, J., Han, T., Dou, H., Ma, S. (2013). Analysis slope safety based on infiltration model based on stratified assumption. Journal of Central South University: Science and Technology, 45(9): 3211-3218.

[8] Lei, J., Xiao, S.G. (2019). Stability analysis method for anchored slopes considering stress dispersion effect in sliding mass due to anchor tensile forces. Journal of Geotechnical Engineering, 41(9): 1724-1730. https://doi.org/10.11779/CJGE201909017

[9] Zhou, X., Zheng, K., Shi, Q., Sheng, J. (2019). Research on highway slope monitoring and warning system. In IOP Conference Series: Materials Science and Engineering, $\quad 569(4)$ : 042002. https://doi.org/10.1088/1757-899X/569/4/042002

[10] Li, X., Zhang, L., Zhang, S. (2018). Efficient Bayesian networks for slope safety evaluation with large quantity monitoring information. Geoscience Frontiers, 9(6): 1679-1687. https://doi.org/10.1016/j.gsf.2017.09.009

[11] Peng, M., Li, X.Y., Li, D.Q., Jiang, S.H., Zhang, L.M. (2014). Slope safety evaluation by integrating multisource monitoring information. Structural Safety, 49: 6574. https://doi.org/10.1016/j.strusafe.2013.08.007 
[12] Karablin, M., Gurev, D., Prostov, S. (2019). Automated stability analysis of soil slopes. In E3S Web of Conferences, 105: 01015 . https://doi.org/10.1051/e3sconf/201910501015

[13] Mukhlisin, M., Khiyon, K.N. (2018). The effects of cracking on slope stability. Journal of the Geological Society of India, 91(6): 704-710. https://doi.org/10.1007/s12594-018-0927-5

[14] Huang, J., Zhao, M., Xu, C., Du, X., Jin, L., Zhao, X (2018). Seismic stability of jointed rock slopes under obliquely incident earthquake waves. Earthquake Engineering and Engineering Vibration, 17(3): 527-539. https://doi.org/10.1007/s11803-018-0460-y

[15] Li, B., Chen, Y., Xu, J., Kong, Q. (2018). A Simple evaluation method of slope safety under rainfall based on experiments of infiltration into soil column. Soil Mechanics and Foundation Engineering, 55(4): 215-222. https://doi.org/10.1007/s11204-018-9528-y

[16] Stacey, C.D., Lintern, D.G., Shaw, J., Conway, K.W. (2020). Slope stability hazard in a fjord environment: Douglas Channel, Canada. Geological Society, London, Special Publications, 500(1): 427-451. https://doi.org/10.1144/SP500-2019-191

[17] Luo, J., Miao, L. (2016). Research on dynamic creep strain and settlement prediction under the subway vibration loading. SpringerPlus, 5(1): 1252. https://doi.org/10.1186/s40064-016-2707-2

[18] Jamalinia, E., Vardon, P.J., Steele-Dunne, S.C. (2020). The impact of evaporation induced cracks and precipitation on temporal slope stability. Computers and Geotechnics, 122: 103506 . https://doi.org/10.1016/j.compgeo.2020.103506

[19] Daraei, A., Herki, B.M., Sherwani, A.F.H., Zare, S. (2018). Slope stability in swelling soils using cement grout: A case study. International Journal of Geosynthetics and Ground Engineering, 4(1): 10. https://doi.org/10.1007/s40891-018-0127-9

[20] Shabani, M., Moallemi, S.A., Krooss, B.M., AmannHildenbrand, A., Zamani-Pozveh, Z., Ghalavand, H., Littke, R. (2018). Methane sorption and storage characteristics of organic-rich carbonaceous rocks, Lurestan province, southwest Iran. International Journal of Coal Geology, 186: 51-64. https://doi.org/10.1016/j.coal.2017.12.005

[21] Zienkiewicz, O.C., Humpheson, C., Lewis, R.W. (1975). Associated and non-associated visco-plasticity and plasticity in soil mechanics. Geotechnique, 25(4): 671689. https://doi.org/10.1680/geot.1975.25.4.671 